\title{
AS REFORMAS DO ENSINO MÉDIO E O PROJETO PROFESSOR DIRETOR DE TURMA: UMA EXPERIÊNCIA EM ARACOIABA-CE
}

\author{
M. C. S. R. LEITE ${ }^{1}$, E. S. MARTINS ${ }^{2}$, M. S. L. LIMA ${ }^{3}$ \\ R. F. BRASIL ${ }^{*}$ e R. G. NORTE (Só incluir quando for aceito) \\ ${ }^{1}$ Instituto Federal do Ceará, ${ }^{2}$ Universidade da Integração Internacional da Lusofonia Afro-Brasileira, \\ ${ }^{3}$ Universidade Federal do Ceará \\ elcimar@unilab.edu.br ${ }^{2}$ \\ Submetido 09/03/2017 - Aceito 27/08/2017 \\ DOI: $10.15628 /$ holos.2017.5754
}

\section{RESUMO}

Este texto buscou compreender as reformas do Ensino Médio, focando no desenvolvimento do Projeto Professor Diretor de Turma (PPDT) como uma inovação proposta pela Secretaria da Educação do Ceará. O PPDT prioriza a realização de um currículo criativo, sintonizado com as demandas sociais contemporâneas, fomentando o diálogo com a juventude e buscando a superação do currículo de concepção fragmentada. A pesquisa de natureza qualitativa foi desenvolvida na Escola de Ensino Médio Almir Pinto, em Aracoiaba-CE e utilizou como estratégias metodológicas, a investigação documental, a observação e entrevistas com docentes. A investigação evidenciou que as reformas do Ensino Médio, de uma forma geral, são carregadas de bons propósitos, mas na prática não se efetivam plenamente, em virtude das condições de precarização, cuja resolução ultrapassa os limites da comunidade escolar e devem ser emanadas dos órgãos mantenedores. No entanto, presenciamos um esforço enorme de todos que fazem a escola para assegurar as condições de trabalho dos professores e a funcionalidade do referido projeto. O conjunto dos dados delineou ainda que o PPDT se configura como um projeto inovador, contribuindo nos processos de ensino e aprendizagem, evidenciando sensibilidade e apoio do núcleo gestor e postura docente de escuta coerente com o perfil do diretor de turma e baseada no diálogo.

PALAVRAS-CHAVE: Reformas do Ensino Médio, Projeto Professor Diretor de Turma, Prática pedagógica

\section{THE HIGH SCHOOL REFORMS AND THE TEACHER DIRECTOR OF CLASS PROJECT: A} Aracoiaba-CE Experience

\begin{abstract}
This paper tried to comprehend the high school reforms, focusing on the development of the Teacher Director of Class Project (TDCP) as an innovation proposed by the Ceará's, Secretary of Education. The TDCP prioritizes the realization of a creative curriculum, akin to present-day social demands, encouraging dialogue with the youth and searching to overcome the fragmented conception curriculum. The research of qualitative nature was developed at the Almir Pinto High School, in Aracoiaba$\mathrm{CE}$ and used as methodological strategies, the documental investigation, observation and teacher interviews. The investigation showed that the High School reforms, in general, are full of good propositions,
\end{abstract}

but actually don't get fully effective, given the decaying conditions, whose solving exceeds the limits of the school community and should be effected by it's maintainers. However, we face an enormous effort from all those who make up the school to ensure the teacher's working conditions and the functionality of the referred project. The overall data outlined that the TDCP configures itself has an innovative project, contributing to teaching and learning processes, evidencing the sensibility and the support from the core management and the teacher stance of coherent listener along with the profile of director of class based on dialogue.

KEYWORDS: High School Reform. Teacher Director of Class Project. Pedagogical practice 


\section{INTRODUÇÃO}

Este artigo é parte de uma pesquisa de Mestrado que investigou o processo de formação contínua dos professores do Projeto Professor Diretor de Turma (PPDT), no contexto das reformas educacionais do Ensino Médio (Leite, 2015). Desenvolvemos a investigação na Escola de Ensino Médio Almir Pinto, Aracoiaba, Ceará. Dentre os projetos pedagógicos inovadores desenvolvidos na referida escola, destacamos o PPDT pela proposta formativa destinada a docentes e discentes. Aos professores, busca prepará-los ao ingresso e permanência no projeto. Aos estudantes, a formação almeja prepará-los para o exercício pleno da cidadania.

O PPDT é embasado nos princípios da razão e da emoção e objetiva a desmassificação da escola pública, buscando construir uma escola que assegure o acesso, a permanência, o sucesso e a formação integral e profissional do ser humano (Ceará, 2013). Nessa perspectiva, o projeto se caracteriza pelo conhecimento personalizado do estudante "a partir do desenvolvimento de um trabalho cooperativo, que oportuniza aos professores conhecer as problemáticas que fazem parte do cotidiano da sala de aula e implicam diretamente no desempenho escolar e no projeto pedagógico da escola" (Ceará, 2011, p. 19).

O projeto prioriza a realização de um currículo criativo, sintonizado com as demandas sociais contemporâneas, fomentando o diálogo com a juventude e buscando a superação de um currículo de concepção fragmentada. Por outro lado, várias situações são perpassadas na atuação e formação do professor diretor de turma, pois além de atuar na formação cidadã, o docente leciona conforme sua formação e sua respectiva lotação.

Com relação aos estudos produzidos sobre formação contínua de professores no Ensino Médio na perspectiva do PPDT, pesquisamos nos bancos de dados do portal da Coordenação de Aperfeiçoamento de Pessoal de Nível Superior (CAPES), na Universidade Estadual do Ceará (UECE), na Biblioteca Digital de Teses e Dissertações (BDTD), e nos CDs dos Encontros Nacionais de Didática e Prática de Ensino (ENDIPE). Com isso, constatamos escassez de estudos diretamente relacionados ao referido projeto.

A pesquisa, de natureza qualitativa, foi desenvolvida com quatro professores lotados nas três séries do Ensino Médio da Escola Almir Pinto. Estes sujeitos apresentam maior tempo de atuação no PPDT na referida instituição de ensino. Realizamos, portanto, um estudo de caso, utilizando-se de observações, entrevistas e análise documental. Como fundamentação deste trabalho recorremos aos estudos de: Martins (2014), Sousa (2013), Santos (2013), Delors (2012), Salgueiro (2010), Vieira (2001).

As emergências do cotidiano escolar e as demais atribuições da docência são fatores limitantes ao exercício da formação contínua, o que de certo modo, parece denotar que o docente não tem tempo para o desenvolvimento de seu processo formativo. Assim, compreendemos que o Professor Diretor de Turma enfrenta problemas com a própria formação. Isso se dá em virtude de docentes com formação em áreas específicas, como Química, Biologia, Física e Letras atuarem no projeto com a responsabilidade de dirigir as turmas, orientando-as sobre questões de aprendizagem, evasão escolar, indisciplina, formação, acompanhamento junto à família, diálogo com os demais docentes, dentre outras atribuições, muitas vezes sem a devida formação pedagógica.

\section{REFORMAS DA EDUCAÇÃO: UM OLHAR A PARTIR DA DÉCADA DE 1990}

A educação é um processo organizado, sistemático e intencional ao mesmo tempo em que é complexa, dinâmica, social e cultural. Está alicerçada em fundamentos, diretrizes e princípios 
educacionais preconizados nos instrumentos legais vigentes. Nas instituições formativas, a educação se constitui nos processos formais e organizados com a finalidade de promover "o desenvolvimento pleno do educando, sua preparação para o exercício da cidadania e sua qualificação para o trabalho", conforme o artigo 20 da atual Lei de Diretrizes e Bases da Educação Nacional, LDB no 9394/96 (Lei 9.394/96, 2013, p. 9).

A história da educação brasileira compreende várias fases: o período colonial, de 1500 a 1822; o período imperial, de 1822 a 1889; a primeira República, de 1889 a 1930; a Era Vargas, de 1930 a 1945; os rumores da educação nacional desenvolvimentista, o período do regime militar de 1964 e o período da transição democrática em 1984, aos dias atuais. No decorrer dos períodos percebemos que as reformas educacionais empreendidas, bem como as políticas públicas voltadas à educação não são condizentes com a realidade, pois o mundo da economia e os interesses do mercado têm sido privilegiados em detrimento dos desafios próprios dos processos de ensino e de aprendizagem (Leite, 2015).

Sabemos que a educação recebe as marcas da globalização, configurando-se como instrumento determinado e determinante nos planos da lógica capitalista. Através da educação os grupos empresariais impulsionam os meios produtivos, capacitam as massas para os serviços de mão de obra a baixo custo financeiro, conforme as necessidades do setor produtivo. Enfim, as determinações do mercado são impostas cotidianamente e não nos damos conta das problemáticas inerentes à exploração desencadeada pela manutenção da elite dominante (Sousa, 2013).

A década de 1990 é mundialmente marcada pelo movimento de valorização da formação e da profissionalização de professor. Especificamente, para o Brasil, é um marco para a educação em virtude dos movimentos reformistas desse período, sobretudo pela instituição da LDB № 9394/96.

A Conferência de Jomtien em 1990 foi elaborada por diversos países e baseou-se na Declaração Universal dos Direitos Humanos ao assegurar o direito à educação para todos. Da Conferência de Jomtien saíram dois documentos, a Declaração Mundial sobre Educação para Todos e o Plano de Ação para Satisfazer as Necessidades Básicas de Aprendizagem.

Do Relatório da Comissão Internacional sobre Educação para o século XXI, destacamos a afirmação de que "[...] atualmente para haver desenvolvimento, é preciso que uma proporção elevada da população possua estudos secundários" (Delors, 2012, p. 109). Sendo uma formação necessária, sobretudo, para os jovens, a América Latina desponta com uma imensa contradição apresentando elevadas taxas de repetência e abandono. Diante dessa problemática, no referido relatório, são apontadas algumas medidas a serem tomadas: reformas sobre formação de professores, ajuda financeira, experiências inovadoras de trabalhos em grupo e recursos tecnológicos que permitam a introdução de materiais didáticos modernos.

Nesse contexto, a LDB № 9394/96 acionou diversas mudanças na educação, impulsionando planos e projetos. Fez surgir as diretrizes, os Parâmetros Curriculares Nacionais, buscou a universalização da Educação Básica, direcionou novos rumos ao funcionamento do Ensino Médio, além da inserção de propostas para o Ensino Superior.

Com isso, a atual LDB determinou vários encaminhamentos em diversos documentos oficiais, os quais se tornaram norteadores da gestão e das políticas públicas em educação no âmbito nacional, além de influenciar estados e municípios a elaborarem leis complementares, resoluções e pareceres sobre as novas reformas educacionais. No caso do Ensino Médio, parametrizou a elaboração das Diretrizes Curriculares Nacionais do Ensino Médio (DCNEM) e dos Parâmetros Curriculares Nacionais do Ensino Médio (PCNEM), dentre outros projetos. 
Nos anos 1990, houve um expressivo crescimento nas matrículas de Ensino Médio, desencadeando forte crise no desempenho dos estudantes. Como um antídoto para essa crise, o governo estabeleceu reformas com garantias de acesso e permanência aos estudantes do Ensino Médio.

A proposta da reforma da última etapa da Educação Básica buscou criar um novo Ensino Médio no sentido de promover as adaptações necessárias ao ensino em atendimento às novas circunstâncias da sociedade contemporânea. Com a reabertura política em 1980, a sociedade ansiava por novos modelos de educação para os jovens. Assim, se fazia necessária a inserção de novos paradigmas escolares, priorizando a dimensão midiática das tecnologias, da ciência e da comunicação (Santos, 2013).

As reformas do Ensino Médio, de uma forma geral, são carregadas de bons propósitos, mas na prática nem sempre se executam, favorecendo uma mera condição de submissão da educação. De acordo com Santos (2013), a educação passou a ser controlada pelo mercado financeiro e subordinada ao setor produtivo. O currículo dito inovador, apresentado à sociedade como o principal vetor de mudanças se deteve exclusivamente na propagação em vez de revolucionar a formação de jovens e adolescentes.

Com isso, a revolução propagada sobre a via formativa não atendeu às expectativas sociais em virtude do comprometimento com a lógica mercadológica dos interesses capitalistas. Os direitos já conquistados cederam lugar à naturalização do possível, cabendo ao Estado somente gerenciar as políticas (Vieira, 2001).

As políticas públicas são elaboradas e implantadas de acordo com o momento histórico, mas entre a proposição e a efetivação há um longo percurso, o que muitas vezes deixa lacunas. No contexto de reformas da Educação Básica, vários projetos foram apresentados à sociedade: alguns de forma isolada, outros concomitantemente. Tais ações influenciam a dinâmica do espaço escolar, embora algumas não sejam nem compreendidas pela comunidade escolar.

As regiões Norte e Nordeste tiveram como alternativa de financiamento o Projeto Alvorada, financiado pelo Banco Mundial. Outra ação do Ministério da Educação - MEC para a redução das desigualdades foi o Programa de Desenvolvimento do Ensino Médio - ProMED, financiado pelo Banco Interamericano de Desenvolvimento - BID.

No ano de 2003, o Ministério da Educação abriu o debate sobre o Ensino Médio e realizou seminários em âmbito nacional para discussão de novas diretrizes curriculares e a universalização da Educação Básica. Até 2007, o Ensino Médio continuou sem o direito de uma fonte financiadora, quando foi implantado o Fundo de Manutenção e Desenvolvimento da Educação Básica e de Valorização dos Profissionais da Educação - Fundeb, assegurando recursos para toda a Educação Básica. Em 2009, o governo federal lançou o Ensino Médio Inovador, experiência piloto testada nos entes federados, nos colégios de aplicação das universidades federais e estaduais e no Colégio Pedro II.

Dessa iniciativa federal se desenvolveram diversas propostas nos estados brasileiros. 0 Ceará reorganizou a proposta do Ensino Médio Noturno, elaborada em 2011 e depois transformada em projeto de lei com aprovação em 2012. Para tanto, o governo estadual utilizouse do Parecer 5/2011 do Conselho Nacional de Educação (CNE), instrumento legal responsável pela atualização das DCNEM (Ceará, 2013b).

O Brasil tem acompanhado o desenvolvimento de reformas definidas anteriormente pelos órgãos que definem os rumos da educação e se mostram comprometidas com seus próprios interesses para a manutenção do ideal capitalista. A centralidade das propostas não condiz com as 
reais necessidades da Educação Básica, de modo especial o Ensino Médio, que continua obtendo resultados abaixo da média nas avaliações de larga escala.

Analisando a história da educação a partir das reformas empreendidas percebemos que ocorreram poucas mudanças na perspectiva da qualidade. Na verdade, as políticas resultantes das reformas não conseguem sua efetiva consolidação. Algumas não chegam a ser totalmente implantadas e já são repensadas, comprometendo desta forma o êxito no processo de aprendizagem e no desenvolvimento intelectual dos estudantes.

Nesse contexto não se discutem os problemas inerentes à aprendizagem. A escola continua ruim e as pessoas continuam frequentando esse espaço todos os dias. Essa característica é resultante das políticas direcionadas à educação, pois encontramos nessas políticas o caráter utilitarista e a ação imediata. A correria do dia a dia nos conduz a ignorar o que realmente acontece no interior dos muros escolares. Esse fato é essencial à política neoliberal, pois favorece o atendimento dos reais interesses dominantes, ou seja, diariamente auxiliamos na construção de uma sociedade desigual da qual não queremos fazer parte. Nessa perspectiva, dois fatores são marcantes nas políticas educacionais: a descontinuidade e a inconclusividade, seja local, regional ou nacional. Tal flagrante denuncia os compromissos e acordos assumidos pelo Brasil junto ao Banco Mundial, dentre outros órgãos internacionais.

Leher (2014) assevera que as políticas governamentais têm produzido uma educação que convém ao capital. Com isso, os sistemas e as reformas estruturais são definidos pelo Banco Mundial, que tem colocado a educação na sua escala de prioridades, determinando assim as diretrizes da política educacional dos países periféricos.

Nesse contexto de mudanças no Ensino Médio, analisamos a experiência do Projeto Professor Diretor de Turma, tomando por base a concepção teórica e a prática, com vistas à apreensão das bases e dos princípios em que a proposta de formação vivenciada pelos docentes vem se desenvolvendo. As políticas educacionais não são apáticas, desinteressadas e/ou neutras. São produzidas e implantadas num contexto, retratando a realidade. Assim, analisamos o que está proposto, percebendo os interesses, e as influências que tem se definido nas forças de controle que determinam as políticas públicas.

\section{PROJETO PROFESSOR DIRETOR DE TURMA: UMA INOVAÇÃO NO ENSINO MÉDIO CEARENSE}

As demandas da sociedade impulsionam a criação de leis, que por sua vez, visam dar um retorno à sociedade. Com base na legislação educacional desencadeou-se o processo de universalização do Ensino Médio em caráter nacional, influenciando as políticas estaduais como referencial de continuidade e legalidade.

As leis atuais do Ensino Médio cearense recebem as influências dos PCNEM, os quais foram elaborados em consonância com a atual LDB. Com base em tais parâmetros, os estados brasileiros criaram seus instrumentos legais, objetivando a normatização, a implantação e a regulamentação de planos e projetos voltados à educação, como o Projeto Professor Diretor de Turma - PPDT.

O PPDT foi criado pela Secretaria de Educação do Estado do Ceará, como instrumento impulsionador das demandas sociais e educacionais, como uma estratégia viabilizadora das metas e ações planejadas a médio e em longo prazo. Assim, são objetivos do Projeto Professor Diretor de Turma:

- Favorecer a articulação entre os professores, alunos, pais e responsáveis, buscando promover um trabalho cooperativo, especificamente, entre professores e alunos, no sentido de adequar estratégias e métodos de trabalho. 
- Tornar a sala de aula uma experiência gratificante, em que todos os professores da turma, familiares, gestão, comunidade escolar, com respectivas parcerias, unam-se com o objetivo de proporcionar uma educação que vise a excelência.

- Manter a assiduidade dos alunos, estimulando sua permanência na escola e elevando o grau de sucesso da aprendizagem.

- Oferecer uma educação sustentável que contemple a formação cidadã do educando, estimulando sua participação na vida social, com a tomada de consciência dos problemas que afetam a humanidade.

- Motivar os alunos para aprendizagens significativas e encorajá-los a ter perspectivas otimistas quanto ao seu futuro pessoal e profissional (Ceará, 2011b, p. 2).

Para o alcance desses objetivos, o PPDT busca desenvolver três funções no interior das escolas: garantir a disciplina dos estudantes, coordenar o ensino para o êxito das aprendizagens e estreitar as relações com a família dos alunos. O desenvolvimento do projeto se ampara nos quatro pilares da educação: aprender a conhecer, aprender a fazer, aprender a viver juntos e aprender a ser (Delors, 2012).

Partindo desses pilares, o estudante é constantemente desafiado a desenvolver as competências cognitiva, produtiva, social e pessoal. Ao professor diretor de turma cabe a tarefa de questionar e oferecer possibilidades para que o educando busque desenvolver 0 conhecimento. Com isso, o diretor de turma faz a mediação e favorece a aprendizagem.

A estrutura de organização e operacionalização do PPDT conta com o apoio de uma célula de coordenação geral na SEDUC, das Coordenadorias Regionais de Desenvolvimento da Educação - CREDE e dos profissionais nas unidades de ensino. As ações são planejadas no Calendário Norteador do Projeto, que contempla o tipo de ação, o responsável por ela e o período de realização.

Em sua carga horária semanal, o professor diretor de turma, tem cinco horas reservadas para o desenvolvimento das tarefas do PPDT: uma hora é utilizada para a aula de formação para a cidadania e as outras quatro são utilizadas para organização de instrumentais, atendimento a pais e/ou responsáveis e estudo orientado (Ceará, 2012). A carga horária destinada ao professor diretor de turma é insuficiente frente à quantidade de tarefas que ele tem para realizar, deixandoo, portanto, sobrecarregado.

O PPDT se desenvolve por meio de algumas estratégias e/ou práticas pedagógicas, tais como: Portfólio, Dossiê da turma, Formação para a Cidadania, Controle da infrequência, Filmes e vídeos, Reunião Bimestral do Conselho de Turma, Sistema Diretor de Turma.

É preciso ressaltar que o termo Diretor de Turma surgiu em Portugal, inicialmente como diretor de classe, depois normatizado para Diretor de Turma. Quando da implantação do projeto no Ceará prevaleceu a nomenclatura Professor Diretor de Turma, conforme Portaria no 882/2010 - SEDUC/GAB, que dispõe sobre a lotação do professor diretor de turma nas escolas de Ensino Médio.

Percebemos uma semelhança entre a experiência portuguesa e a experiência cearense tanto nas dimensões de atuação como também nas atribuições e no perfil do docente. Na experiência do Ceará, o propósito governamental buscou aproximar as atribuições do diretor de turma à direção geral, à gestão pedagógica e à família.

O referido projeto está em diálogo com três dimensões complexas. A direção recebe forte pressão social para dar resultados positivos e imediatos. A gestão pedagógica requer formação contínua, acompanhamento dos processos de ensino e aprendizagem, bem como o constante 
desafio das inovações midiáticas e tecnológicas. A família no contexto atual vive as consequências das desigualdades sociais, em um mundo competitivo e de incertezas.

Aliam-se a essas questões as características do perfil do professor diretor de turma, que muitas vezes não tem o tempo necessário para preparar-se para essa demanda. Isso se dá, sobretudo, em virtude do grande contingente de docentes cearenses que passaram a ocupar o cargo de professor diretor de turma (Ceará, 2011b). Nesse sentido,

\footnotetext{
No caso do director de turma, este saber especialista decorre da sua condição de professor e não da condição de gestor pedagógico intermédio pois, como é sabido, a inexistência de formação adequada para o exercício do cargo é uma realidade que perpassa todos os modelos de gestão das escolas, até à actualidade (Salgueiro, 2010, p. 40).
}

É interessante um processo de formação contínua aos diretores de turmas, bem como a outros professores para que também sejam formados para futuras substituições no exercício do cargo. As formações devem orientar as decisões, o acompanhamento pedagógico e preparar para o desempenho de atuação junto ao conselho de turmas (Favinha, Góis \& Ferreira, 2012). Sobre a necessidade de formação especializada,

\footnotetext{
Ora, é exactamente a inexistência de uma preparação específica para o exercício de funções de gestão intermédia que impede o director de turma de lançar mão do poder cognoscitivo para se impor junto dos seus pares. E este constrangimento fragiliza a sua condição de líder. Constata-se uma evidente dissonância entre o discurso oficial sobre a relevância desta estrutura pedagógica intermédia e as condições efectivas para o seu desempenho (Salgueiro, 2010, p. 30-31).
}

Diante dos motivos elencados e das atribuições inerentes ao cargo, podemos perceber o enorme desafio para o exercício do cargo de professor diretor de turma. Os docentes, de uma maneira geral, estão em constante processo de formação para que exerçam bem a sua tarefa. No caso específico do PPDT, fica ainda mais evidente a necessidade de uma contínua formação, posto que o profissional é responsável por uma turma, se relaciona com seus pares, com a direção e a coordenação pedagógica da escola, com os estudantes e seus familiares.

\section{PDDT NA EEM ALMIR PINTO: UMA EXPERIÊNCIA REFLETIDA NA PRÁTICA}

A Escola de Ensino Médio Almir Pinto, situada em Aracoiaba-Ceará, foi inaugurada em 12 de outubro de 1953, com a denominação de Grupo Escolar Almir Pinto. Em 1972, o grupo escolar é transformado em Escola de $1^{\circ} \mathrm{Grau}$, ofertando até a $8^{\text {a }}$ série (atual nono ano). Na década de 1980, mediante a implantação de cursos profissionalizantes, a Escola Almir Pinto enfrenta mais uma alteração em sua nomenclatura, passando a ser Escola de $1^{\circ}$ e $2^{\circ}$ Graus Almir Pinto. Nos últimos anos, o Ensino Fundamental é transferido para a rede municipal de ensino e a escola passa a ofertar somente o Ensino Médio.

A investigação contou com a participação de quatro professores que atuam no PPDT. Para garantir o anonimato dos sujeitos, os professores são identificados por codinomes de intelectuais da Semana de Arte Moderna: Anita Malfatti, Tarsila do Amaral, Oswald de Andrade e Manuel Bandeira. Na sequência, discutimos os dados coletados durante as entrevistas a partir das categorias: Formação, Gestão e Inovação, contemplando um movimento de avanços e retornos ao ponto de partida, considerando a pessoa, o cargo de professor e o ingresso na função de diretor de turma. Verificamos que saberes retornam da experiência do diretor de turma para o cargo de professor. 
Os três aspectos acima definidos são essenciais ao professor para que ele possa desenvolver sua função na perspectiva de um currículo que atenda as demandas da sociedade moderna. Essa concepção reflete uma posição de atitude profissional fundamentada na dialética entre as condições da realidade educativa e as formas de viver e desenvolver a profissão frente às demandas da própria profissão (Contreras, 2012).

Perguntamos aos sujeitos sobre a formação específica para atuar no PPDT. Abaixo seguem os relatos deles a esse respeito:

Hoje a CREDE não está desenvolvendo as formações. De três anos para cá mudou muito e o projeto ficou muito digital. Quando tem formação é só com a coordenadora do projeto em nossa escola. Ela vai e passa para a gente. Este ano até agora ainda não se falou em formação. No início deste ano tivemos formações, mas são sempre fora da carga horária (Manuel Bandeira).

Agora, as formações acontecem por representação. Os novatos começam e passam metade do ano sem a formação. A formação não dispõe de material tipo apostila. A CREDE trabalha o projeto só com slides. A única apostila que nós recebemos foi do projeto Cultura de Paz para trabalhar a formação cidadã. Do projeto mesmo nunca recebemos nada (Oswald de Andrade).

Quando assumi pela primeira vez tive uma formação de diretor de turma. Foram duas formações na CREDE desde que estou diretor de turma. Tivemos também um momento aqui com a coordenadora do projeto na escola, mas foi tipo um planejamento. Ultimamente, não tem é nada e até a formação está restrita (Anita Malfatti).

Uma coisa que é muito falha no PPDT é que as formações acontecem no mês de agosto. Então até o mês de agosto você se vira como pode. Fazemos o projeto acontecer antes da formação. Ano passado nem a formação funcionou e aconteceu apenas um momento na escola. Não teve nada. Cortaram a bolsa, a blusa e o kit. Esse material é necessário para a preparação das atividades e as aulas da formação cidadã (Tarsila do Amaral).

A ausência de formação adequada dificulta o pleno desenvolvimento de um ensino de qualidade e, consequentemente, a inovação pedagógica. Nesses termos, a formação de professores é a via essencial no sentido de possibilitar valores pessoais fundamentais à profissão para dotar o professor de capacidades intelectuais. A formação de professores precisa ser autêntica no atendimento às necessidades docentes. Está para além da aquisição de técnicas e de informações científicas. A pesquisa deve embasar os processos formativos para que assim fortaleça a identidade do professor a partir de suas vivências práticas (Pimenta \& Ghedin, 2012).

Os sujeitos demonstraram preocupação com a ausência da formação, sobretudo, a formação específica para atuação no Projeto. De acordo com Veiga e D'Ávila (2008) e Martins (2014), a formação de professores trata-se de um direito e a esfera pública tem o dever de fomentá-la. Nessa perspectiva, a formação assume o caráter de inacabamento, o que se prolonga durante toda a vida profissional, tornando-se indispensável à preparação dos docentes.

Para Candau (2010), a formação contínua não se limita a cursos rápidos, seminários, palestras ou conhecimentos técnicos. Ela se fortalece no trabalho crítico, nas práticas de construção e reconstrução do conhecimento de forma interativa, demarcando a identidade pessoal e profissional do professor.

Verificamos um sentimento de inquietação dos diretores de turmas quando abordam a falta de formações e a superficialidade formativa. Tais profissionais percebem a ausência de aprofundamento nas formações, especificamente nas formações em formato de seminário, com mero repasse de informações com técnicas limitadas. Evidenciaram também a formação como 
direito da categoria e dever das instituições formadoras. Essa é uma lacuna encontrada e um assunto bastante discutido no contexto atual da profissão docente, como também, o quadro situacional das condições para a realização das formações.

A formação docente deve possibilitar as capacidades intelectuais para levar o professor à produção do conhecimento para a interpretação das situações-problema "complexas em que se situa, e, por outro lado, envolver os professores em tarefas de formação comunitária para dar educação escolarizada a dimensão de vínculo entre o saber intelectual e a realidade social, com o qual deve manter estreitas relações" (Imbernón, 2011, p. 42).

Questionamos os sujeitos sobre a gestão de sala de aula. Assim, abordamos sobre as ações pedagógicas em detrimento das atividades burocráticas do PPDT. Vejamos os relatos:

É um desafio dar conta das ações pedagógicas e ser diretor de turma. Os alunos separam muito bem, compreendem como duas atuações diferentes. Nas atividades pedagógicas, me inspiro nas boas professoras. Uma professora que me marcou muito foi a dona Elvira. Foi na sala dela aos catorze que me tornei professor sem saber. Eu dava aula para os colegas à época mesmo com a resistência para ser professor (Manuel Bandeira).

Durante uma aula não dá tempo para ser muito pedagógico. São muitas atividades para serem desenvolvidas. No primeiro ano tem uma apostila que é voltada a trabalhar os valores. Cada mês é para ser trabalhado um valor, como paz, amor, respeito. Quando não dá tempo a gente trabalha outros temas alternativos. Estes temas são sugeridos nas reuniões diagnósticas. Então a gente faz um apanhado do que vai ser trabalhado e prioriza as ações pedagógicas dentro das possibilidades (Oswald de Andrade).

Atuar pedagogicamente é um desafio para quem é das ciências exatas. Sinto muita necessidade de uma formação pedagógica. A ciência da natureza é muito objetiva. Tenho dificuldade de fazer dinâmicas. Penso que o bom professor nunca sabe de tudo, não pode parar de estudar, nem guardar suas aprendizagens para si. Sempre dividir o saber com os outros; este é o segredo do sucesso pedagógico (Anita Malfatti).

O projeto em minha opinião é perfeito. Se tivesse mais tempo diminuiria ainda mais o abandono escolar. Através do projeto foram resolvidos muitos problemas. O desafio maior é o tempo. Se fossem 100 horas só para o projeto os resultados seriam melhores. Deixamos de fazer o estudo orientado, que é uma ação pedagógica de grande importância. Atualmente não é realizado por falta de tempo. Em que momento eu vou estudar com meus alunos num horário extra à carga horária? (Tarsila do Amaral).

O espaço da sala de aula é o lugar de lançar descobertas, perpassa a relação do professor e do aluno com a produção do conhecimento. A proposta do PPDT propõe uma quebra de paradigma com antigas práticas do cotidiano escolar. Mesmo reconhecendo as dificuldades do fazer pedagógico em sala de aula, percebemos nas falas dos sujeitos um indicador favorável à produção de conhecimentos, ou seja, o favorecimento da relação de proximidade do professor e do aluno. Sabemos que para a escola alcançar seu propósito de formar os estudantes e ser autêntica na gestão pedagógica de forma compartilhada, se faz necessário sua edificação na coletividade, na contextualização e na inserção de todos os envolvidos no processo educativo.

Alarcão (2011) nos ajuda a pensar a essência de uma escola na dimensão reflexiva, ou seja, a instituição que cria suas próprias regras, presta contas de seus resultados, autovalia-se frequentemente, valoriza a produção do conhecimento de seus profissionais e, acima de tudo, não dita a formação de professores. 
Nessa escola, a gestão pedagógica integra as pessoas, insere o aluno e também todas as pessoas que estão no entorno da escola. Esses membros são colocados no centro da discussão educativa. Por fim, a escola reflexiva apresenta domínios pedagógicos comuns às disciplinas e ao modo como os professores organizam e gerenciam as atividades de sala de aula. Isso significa ação planejada nos princípios pedagógicos, o que postula um enorme desafio aos seus professores e gestores.

Percebemos na fala dos sujeitos fragilidades em desenvolver uma prática consolidada no princípio da reflexão. A gestão de sala de aula é suprimida pelas normas e afazeres diários impostos pelas questões próprias do sistema escolar. $\mathrm{O}$ ideal de projeto pedagógico perde força no tarefismo, comprometendo dessa forma "[...] a existência de um tipo de organização e de gestão que caracterizarei como: participada, coerente, desafiadora e exigente, interativa, flexível e resiliente face às situações, avaliadora, formadora" (Alarcão, 2011, p. 99). Observamos nos sujeitos um esforço para superar o tarefismo e as exigências impostas diariamente, priorizando mais tempo qualitativo à gestão da sala de aula.

Sem perder o fio condutor dessa discussão, vamos analisar o PPDT na perspectiva da inovação. Esse projeto se apresenta como um instrumento de auxílio à gestão, favorecendo a realidade escolar. As políticas e os projetos inovadores analisados no campo das pesquisas não se esgotam neles mesmos. Dessas investigações surgem outros encaminhamentos, como instrumentos norteadores de maior teor moderno, porém não são colocados em prática como deveriam. Assim, convivemos com os entraves das políticas que se apresentam como resposta às demandas educacionais e, na maioria das vezes, não atendem verdadeiramente às reais necessidades.

Dentro do que foi possível analisar sobre a inovação do projeto, investigamos quais saberes foram transportados da pessoa para a função docente e depois verificamos dos saberes docentes quais os que chegaram ao cargo de diretor de turma. Os sujeitos disseram que:

\footnotetext{
Como músico profissional, aprendi que o todo é feito de partes. Cada um tem que fazer a sua parte para que a peça musical aconteça. Para eu fazer a harmonia alguém tem que fazer a melodia. Para atuar no PPDT trago esse aprendizado, faço a minha parte e penso que cada um tem que fazer também a sua (Manuel Bandeira).
}

Ser tranquilo, a perseverança e o modo de lidar com os alunos, de ter gestão na sala de aula. Eles diferenciam a função do professor em relação às do diretor de turma. A própria graduação me ajudou bastante para trabalhar em sala de aula e, consequentemente, me conduziu ao projeto (Oswald de Andrade).

Um dia encontrei um aluno que guardava o texto Recomeço, do Drummond, que eu havia dado. Mantinha dentro da carteira dele. Nessa época estava meio desestimulada para preparar as aulas. Depois disso, decidi continuar a fazer o que eu acredito. Voltei a inovar nas minhas aulas, pensando nos alunos. Se todos não aproveitam pelo menos fica alguma coisa para alguns (Anita Malfatti).

Gosto também muito de trabalhar com artesanato e isso me acompanha na função de diretor de turma. Procuro ser criativa com meus alunos. Elaboro projeto para eles, sobretudo, para os jovens que estão envolvidos com coisas indevidas. Alimento constantemente o sentimento e o compromisso de poder fazer mais pelos alunos (Tarsila do Amaral).

As inovações não surgem do nada, nem são aleatórias. São criadas e fortalecidas no bojo da coletividade e se destinam aos anseios do contexto atual, presente na instituição de ensino. "Pensar na melhoria do ensino e na sua qualidade efetiva aponta para as possibilidades de 
promoção de inovações [...] Essa qualidade não é apenas melhoria naquilo que já existe, mas em criar, recriar e acima de tudo inovar" (Sousa, 2013, p. 65).

Nessa perspectiva, o termo inovação compreende diversos significados na sociedade atual. Esse universo de significados variados compõe os níveis de inovação, os quais vão desde a "superficialidade, nos contextos educacionais aos níveis mais complexos correspondentes a transformação da realidade educacional" (Sousa, 2013, p. 68).

Portanto, compreendemos que a inovação ultrapassa a dimensão da novidade na era digital, tendo em vista que a sociedade da informatização e da comunicação requer um conceito mais elaborado sobre as inovações. A descoberta de hoje poderá ser superada amanhã. No futuro próximo vão surgindo novas invenções, algo proveniente da incerteza. Isso requer novas pesquisas e investimentos na produção de conhecimento em atendimento às necessidades sociais do contexto atual (Masetto, 2011).

Diante dos desafios do século XXI, a formação docente precisa ser inovadora e, para tanto, deve apresentar um cenário que configure novos rumos no mundo das incertezas. A revolução digital inserida pelas redes sociais no Brasil e no mundo tem interferido no modo de vida das pessoas, tem possibilitado movimentos de contracultura, e promovido a explosão de vários elementos antes nunca imaginados na sala de aula.

Essa situação social requer dos professores nova forma de pensar, ser e agir. São valores de vida e formação que estão em questão. Diante da incompletude, os professores buscam constantemente aprofundar os conhecimentos e fazer relação dos saberes com outras culturas, articulando novas perspectivas, buscando preparação para intervir com uma postura inovadora na educação.

Nesse sentido, observamos que os sujeitos buscaram dentro de suas possibilidades se fazerem inovadores. Estão inseridos no grupo que apresenta valores críticos e características inovadoras. Esses professores galgaram um caminho formativo que os conduziram a novos conhecimentos pedagógicos, a ter um perfil de enquadramento nos padrões profissionais definidos pela instituição de ensino. Assim, têm se mantido na lotação pretendida à medida que se esforçam na qualificação para atuação no PPDT. Esses profissionais perceberam que o mundo está em movimento, que as práticas antigas estão sendo superadas e que o conceito de docente já não é mais o mesmo.

Os sujeitos se autodefinem como profissionais que agregam valores de sua formação pessoal como essenciais à sua profissão. Tais valores da vida pessoal, como também da vida profissional os fizeram chegar ao cargo de diretor de turma. Esses valores são utilizados como capacidades essenciais à preparação dos jovens para enfrentamento de situações difíceis na tentativa de fazer-lhes pensar sobre a complexidade em vez da linearidade.

A prática de saber ouvir os jovens, de ajudar-lhes a resolver os conflitos existentes foram os saberes credenciadores ao cargo de diretor de turma. Não que esses saberes tenham proporcionado uma atuação fácil; muito pelo contrário, esses saberes os colocaram para desempenhar algo muito mais complexo. Ao assumir o cargo de diretor de turma, os professores precisaram mudar posturas antigas, aprenderam a resolver situações-problema, o que demanda mobilização, conhecimento, articulação e estratégias inteligentes. O PPDT se apresenta como uma ação inovadora, que impõe constantes desafios. Os diretores de turma precisam pensar constantemente como agir diante dos desafios cotidianos. 


\section{CONCLUSÃO}

Analisando a história da educação a partir das reformas empreendidas, percebemos que ocorreram poucas mudanças na perspectiva da qualidade. As políticas resultantes das reformas não conseguem sua efetiva consolidação. Algumas não chegam a ser totalmente implantadas e já são repensadas, comprometendo desta forma o êxito no processo de aprendizagem e no desenvolvimento intelectual dos alunos.

O percurso dos professores investigados demonstra atitudes comportamentais de amadurecimento profissional na caminhada das formações. São graduados em Química, Biologia, Física e Letras, que iniciaram a docência com pouca formação pedagógica e durante o desenvolvimento da carreira foram alargando a dimensão formativa.

Os diretores de turma se consideram com um perfil conciliador de conflitos e durante a experiência com o projeto desenvolveram ainda mais a capacidade de saber ouvir. Defendem a necessidade de formação específica e contínua para o projeto, como também, uma valorização financeira e o apoio de outros profissionais. Tais profissionais veem na formação a possibilidade de melhoria da atuação docente e buscam participar dos momentos formativos apesar das dificuldades em conciliar os horários e dias definidos com a sua carga horária.

Os problemas inerentes ao PPDT poderão ser de fácil resolução ou de frustração, pois algumas vezes podem esbarrar em outras instâncias que vão além dos muros da escola, ultrapassando a contribuição e o controle do professor. Embora existam atribuições claras ao cargo, o cotidiano escolar é permeado por uma diversidade de problemas que às vezes requerem a intervenção de profissionais especializados.

O PPDT tem contribuído para a consolidação da identidade do Ensino Médio como a última etapa da Educação Básica. Os professores diretores de turma se esforçam para superar os afazeres burocráticos e administrativos, buscando dentro de suas possibilidades garantirem a aprendizagem de seus estudantes, desenvolvendo o processo formativo, numa perspectiva criativa e inovadora.

\section{REFERÊNCIAS}

Alarcão, I. (2011). Professores reflexivos em uma escola reflexiva. São Paulo: Cortez.

Candau, V. M. (2011). Magistério: Construção cotidiana. Petrópolis-RJ: Vozes.

Ceará. (2010). Portaria-GAB № 882/2010. Estabelece as normas para lotação de professores nas escolas públicas estaduais. Recuperado em 5 outubro, 2014, de http://imagens.seplag.ce.gov.br/pdf/20101223/do20101223p01.pdf

Ceará. (2011). Diretrizes. Fortaleza: Secretaria da Educação Básica.

Ceará. (2011b). Projeto Professor Diretor de Turma. Folder. Fortaleza: Seduc/Anpae.

Ceará. (2012). Portaria № 1091/2012-GAB. Diário Oficial do Estado. Série 3, Ano IV, № 242.

Ceará. (2013). Projeto Professor Diretor de Turma. Seminário Nacional do Observatório da Educação. Brasília.

Ceará. (2013b). Ensino Médio Noturno: Projeto de Reorganização Curricular. SEDUC, Fortaleza. Contreras, J. (2012). Autonomia de professores. São Paulo: Cortez.

Delors, J. (2012). Educação: um tesouro a descobrir. São Paulo: Cortez.

Favinha, M.; Góis, M. H.; Ferreira, A. (2012). A importância do papel do diretor de turma enquanto gestor do currículo. Recuperado em 6 outubro, 2014, de 
https://dspace.uevora.pt/rdpc/bitstream/10174/8185/1/Artigo\%20Revista\%20Temas\%20e\%2 OProblemas.pdf

Imbernón, F. (2011). Formação docente e profissional: formar-se para a mudança e a incerteza. São Paulo: Cortez.

Leher, R. (2014). Organização, Estratégia Política e o Plano Nacional de Educação. Recuperado em 5 fevereiro, 2015, de http://marxismo21.org/wp-content/uploads/2014/08/R-LeherEstrat\%C3\%A9gia-Pol\%C3\%ADtica-e-Plano-Nacional-Educa\%C3\%A7\%C3\%A3o.pdf

Lei no 9.394, de 20 de dezembro de 1996 (2013). Lei de Diretrizes e Bases da Educação Nacional. Centro de Documentação e Informação. Brasília: Edições Câmara.

Leite, M. C. S. R. (2015). A formação contínua do professor diretor de turma no contexto das reformas do ensino médio. Dissertação de mestrado, Universidade Estadual do Ceará, Fortaleza, CE, Brasil.

Masetto, M. T. (2011). Inovação curricular no ensino superior. Revista e-curriculum, 7(2), 1-20

Martins, E. S. (2014). Formação contínua e práticas de leitura: o olhar do professor dos anos finais do ensino fundamental. Tese de doutorado, Universidade Federal do Ceará, Fortaleza, CE, Brasil.

Pimenta, S. G., \& Ghedin, E. (2012). Professor reflexivo no Brasil: gênese e crítica de um conceito. São Paulo: Cortez.

Salgueiro, A. R. (2010). O director de turma como gestor do projecto curricular - Um estudo de caso. Dissertação de mestrado, Universidade de Lisboa, Lisboa, Portugal.

Santos, J. M. T. (2013). Políticas para o Ensino Médio: Recontextualizações no contexto da prática. 36a Reunião Nacional da ANPEd. Goiânia: ANPEd.

Sousa, A. L. L. (2013). Formação Profissional em Fisioterapia: o desafio dos avanços curriculares nos projetos pedagógicos da universidade pública. Tese de doutorado, Pontifícia Universidade Católica de São Paulo, São Paulo, SP, Brasil.

Veiga, I. P. A., \& D'Ávila, C. (2008). Profissão docente: novos sentidos, novas perspectivas. Campinas: Papirus.

Vieira, E. (2001). A política e as bases do direito educacional. Cadernos Cedes, 55, 9-29. 